\title{
Die Unterlederfabrikation
}




\title{
Die \\ Lederfabrikation \\ Praktisches Handbuch für die gesamte Lederindustrie
}

\author{
von \\ Joseph Borgman \\ weiland Fabrikdirektor und Lehrer an der Deutschen Gerberschule \\ zu Freiburg in Sachsen \\ und \\ Oskar Krahner \\ Direktor und Redakteur der Deutschen Gerberzeitung Berlin
}

Zweite, durchgesehene

und neubearbeitete Auflage der „Rotlederfabrikation“

herausgegeben von

Professor Dr. Hans Friedenthal

I. Teil: Die Unterlederfabrikation

II. Teil: Die Oberlederfabrikation 


\title{
Die \\ Unterlederfabrikation
}

\author{
Praktisches Handbuch
}

für die

Herstellung sämtlicher Unterledersorten

von

Joseph Borgman und Oskar Krahner

Zweite, durchgesehene und neubearbeitete Auflage

von

Professor Dr. Hans Friedenthal

Berlin

Mit 43 Abbildungen

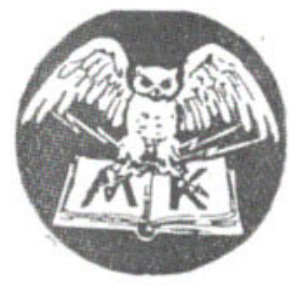

BERLIN W

VERLAG von M. KRAYN

1923 
Alle Rechte, namentlich das der Uebersetzung vorbehalten.

Druck von Rosenthal \& Co.. Berlin NW 21. 